\title{
Transformative Potential of Constructivist Blended Problem- Based Learning in Higher Education
}

Roisin Donnelly

Technological University Dublin, roisin.donnelly@tudublin.ie

Follow this and additional works at: https://arrow.tudublin.ie/ltcbk

Part of the Educational Methods Commons, and the Higher Education Commons

\section{Recommended Citation}

Donnelly, R. (2008). Transformative Potential of Constructivist Blended Problem-based Learning in Higher Education. In C. Payne (Ed.), Information Technology and Constructivism in Higher Education: Progressive Learning Frameworks. Hershey, PA: Information Science Reference, 2008.

This Book Chapter is brought to you for free and open access by the Learning Teaching \& Assessment at ARROW@TU Dublin. It has been accepted for inclusion in Books/Book Chapters by an authorized administrator of ARROW@TU Dublin. For more information, please contact arrow.admin@tudublin.ie, aisling.coyne@tudublin.ie,gerard.connolly@tudublin.ie.

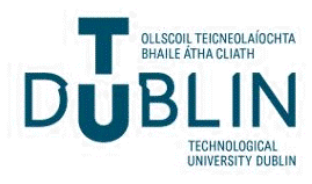




\title{
Transformative Potential of
}

\section{Constructivist Blended Problem-based \\ Learning in Higher Education}

\author{
Roisin Donnelly \\ Learning and Teaching Centre \\ Dublin Institute of Technology \\ 14 Upper Mount Street \\ Dublin 2 \\ Ireland \\ Tel 0035314027886 \\ Fax 0035316767243 \\ Email: roisin.donnelly@dit.ie
}




\begin{abstract}
This chapter critically explores the design and implementation of a blended problem-based learning (PBL) module for academic professional development in higher education. A core aspect of the chapter is the overview of the design framework used for the application and specific use of learning technologies in the PBL module. As it would appear that e-learning courses are often lauded on the basis of their constructivist approach to learning, but in reality sustained interstudent contact and discussion can be difficult, an underlying purpose of the chapter is to show how interactional analysis helps in understanding the potential of transformative pedagogy within blended PBL. This chapter aims to highlight how emerging constructivist theories of learning may be applied to the blend of PBL and e-learning. It addresses the need for an analysis of the interactions taking place in blended PBL with a specific focus on academic staff who are engaged in professional development in higher education in Ireland. It applies the relevant constructivist theories to the face-to-face PBL tutorials, online discussions, focus group interview texts and reflective papers generated over two years in a professional development module involving 17 academic staff. The chapter concludes with an analysis of the difference that the blended delivery made to both tutors and participants and discusses the design implications of a blended PBL model for the practice of academic development.
\end{abstract}

\title{
KEYWORDS
}

Academic development; blended learning; computer mediated conferencing; e-learning; group learning; interactional analysis; online tutoring; social constructivism; student centred learning; transformative pedagogies. 


\section{Transformative Potential of Constructivist Blended Problem-based Learning in Higher Education}

\section{INTRODUCTION}

Some of the most innovative e-learning applications used today tend to be among advocates of a constructivist approach to learning who have high levels of information and communication technology (ICT) skills, often in higher and adult education. Influenced by constructivist philosophy and new learning technologies, there is increasing interest among higher education faculty/academic staff in authentic activities as a basis for learning. In recent years, the integration of constructivist learning theory and problem-based learning (PBL) strategies with online scenarios and virtual role playing have taken student activities to the heart of the curriculum. This chapter explores the constructivist nature of blending face-to-face and online PBL to offer opportunities to educators in higher education seeking to confront pedagogical challenges in their on-the-ground practice.

It is useful here for the context of the study discussed in this chapter to make explicit definitions of the key principles involved: transformative pedagogy, problem-based learning and blended learning. From a definitional perspective, descriptions of transformative pedagogy originated in the adult education literature and Myers (2006) believes it has been regarded as an approach to teaching that encourages students to grapple with disorienting dilemmas, critically examine their assumptions related to the contradictory information, seek out additional perspectives, and ultimately acquire new knowledge, attitudes and skills in light of these reflections - all in order to experience personal and intellectual growth.

Many definitions currently exist in the literature for blended learning; however, the definitions seem to converge around the idea of synthesizing e-learning with the more traditional forms of teaching and learning, drawing together the "e" with the classroom, the laboratory, the seminar and the tutorial setting. PBL is an educational strategy that involves the presentation of significant, complex and "real-world" problems to students that are structured in such a way that there is not one specific correct answer or predetermined outcome. The blended learning used in this study has been described as a form of complex blending in that it combines face-to-face and 
online PBL. Savin-Baden (2006) has concluded that the objective of combining PBL and elearning is in itself complex. She also recognises that this terminology is problematic since it offers little indication "about the ways in which technology is being used, areas where students interact, which tools are used, how learning materials are selected and applied and the extent to which any of these fit with PBL" (p. 4).

\section{Issues, Controversies, Problems}

Blended PBL is a growing field of study whose impact is becoming increasingly relevant in higher education in a period of continuing rapid change and within a set of global challenges. These challenges affect the teaching staff in higher education today, and as a result, the faculty/academic development experts who are charged with easing their transition through the sea-change in how education is delivered. There is currently little evidence of any comprehensive studies into the transformational potential of constructivist blended PBL in faculty/academic development; critical research to date has been sporadic at times but widespread and plentiful in addressing such issues as what is blended learning or PBL and how online PBL occurs.

Although the PBL tutorial is the central and key learning encounter in PBL curricula, and the integration of technology has increased in practice in recent years, surprisingly very little research has been done on what actually happens in blended PBL tutorials. The purpose of this study is to provide research-based information about the realities of delivering a constructivist PBL programme using technology. Central to this study is the role of interactivity and technology in supporting it in the contemporary PBL tutorial classroom, both real and virtual. In view of the constructivist approaches to education now increasingly coming to prominence, it is appropriate to enquire into the perceptions of the academic staff in order to further the effectiveness of interactivity in a blended environment. It is hoped that the presentation and exploration of issues faced by those working with blended PBL tutorial groups will provide fellow researchers and practitioners in the field with a rich text from which they can form their own ideas and researchbased practice. 


\section{Purpose of the study}

In Ireland, and indeed in the host Institute where the study was conducted, as elsewhere, the use of online technologies has become an increasingly important challenge in academic staff development. There has been a demand for higher education institutions in Ireland to put elearning initiatives and the accompanying academic staff training and development firmly on their agendas. Informally enthusiasm among academic staff for e-learning continues to grow and where explicit institutional policies are lacking, pressure on lecturers to engage with new technologies is coming from students and from their own peers. Alongside this, new pedagogical approaches emerge on the educational scene to support complex, flexible and integrated learning and the development of professional competencies. Although not new, PBL is one which appears to have captured the imagination and support of teachers; there has been a growing interest in the last few decades, particularly in the collaborative construction of knowledge through active learning and the importance of higher-order skills such as problem solving. Given our increasingly networked society, interest has grown in innovative conceptualizations of pedagogies such as problem-based learning and in where and when to use them.

Kirkup \& Kirkwood (2005) reported that over the past 15 years the discourse about higher education teaching has been couched in terms of transformation of learning and revolution in technology. However, there has been a sense of disappointment that the transformative potential of technology is being missed or resisted. Transformative learning theory is being proposed in this study as a means to understand the complexities of education in an age where information and communication technologies (ICTs) are constantly reshaping and redefining our accepted notions of what it means to teach and learn in a higher education environment. This study contributes to the gap in the literature by illustrating how academic staff can implement transformative pedagogy such as PBL in their blended classes.

What perpetuated the need to have the participants engage in the blended PBL activities was the fact that many academic staff still lack the online experience of the Internet generation, and so do not feel as confident in an online environment as they do in a traditional classroom setting. In this context, the problem is a social rather than a pedagogic one and lecturers may need to experience being online students themselves in order to gain the necessary confidence to move to facilitating 
an online environment. Increasingly it is also becoming important not just to make such training more accessible, but explicitly designed to produce qualitatively improved pedagogy (Ham \& Davey 2005, p. 263). It is important to ensure that the lecturer's first experience of an online environment is positive, one that will allow them to see the pedagogic possibilities at their disposal.

A blended rather than a fully online approach was chosen. While there are a number of successful fully online degrees reported on offer today such as those through 'Ultraversity', a distance learning subsidiary of Anglia Ruskin University, where all students are taught fully online. generally fully online qualifications suffer from low numbers of enrolled students and /or low retention rates, perhaps indicating that this is not always what the majority of students seek for their university education (Hoare, 2006). Arguably blended approaches have emerged as an alternative to fully online programmes.

The emphasis in this next section of the chapter is on an examination of the blended environment and PBL tutorial used on this postgraduate programme. It will explore the impact of blended PBL on the learners, particularly the impact of shifting back and forth between face-to-face (f2f) and virtual environments. The blended PBL approach to learning in this study was chosen because it is both varied and flexible and introduces questions about what it means to be a problem-based learner and tutor in both a classroom and online setting. Finally, consideration is given to whether the course design and not the technology caused both the benefits and the problems, or whether it was a blend of both.

\section{Introduction to the Blended PBL Module}

Issues related to the design and implementation of blended learning environments have increasingly surfaced in recent years, as technological advances continue to blur the lines between distributed learning and traditional campus-based learning. This has raised questions about advances in technology during that last decade that have brought challenges and opportunities to the ways in which individuals are educated and trained, in particular through blending online and f2f instruction. 
The focus of the research reported here is a postgraduate programme in higher education learning and teaching which was developed in 2001, and has over 100 graduates today. The 'Designing elearning' module at the heart of this study is one of a number of ten week modules which carry ten ECTS (European Credit Transfer and Accumulation System) credits. The 17 participants on the module in this study were all either lecturers or educational support staff teaching in varied subject disciplines in higher education.

The programme grew out of identification of a specific need. The nature of these academic staff's varied work responsibilities today is complex, with demands on their time (ranging from lesson preparation, student support and research, to staff meetings, curriculum development) pulling them in many directions. In my experience as an academic developer, over a number of years, there have been a significant number of academic staff who have been inducted and trained to set up the basics of operations in technologically mediated learning environments across the Institute, but few who have been developed further in terms of pedagogical training. Indeed, of those staff who have expressed a wish to engage with e-learning, on average more than half of those who attend an initial day-long introductory session do not proceed immediately to employ it as part of their practice, citing time constraints as the main inhibiting factor (Donnelly \& O'Rourke, 2007). As a result of all the pressures academic staff face in today's higher education environment, Donnelly \& O'Farrell (2006) have argued that for their own professional development, they need to be provided with streamlined learning experiences which deliver essential topics and learning materials in readily accessible formats. A central challenge was to create and sustain quality learning environments of enduring value for these teachers.

Motivation of the participants in the module was important. Consideration of motivational factors could have a large impact on module completion and work levels of participants. A pre module questionnaire had been distributed to all participants at the outset of the study to gauge their reasons for wanting to undertake a blended PBL approach to their learning. It is suggested here that the need to encourage engagement amongst academic staff with regard to their e-learning and pedagogical professional development opportunities has never been greater. By so doing, participants would be enabled to experience, discuss and reflect on issues related to teaching and learning in a blended environment. This could thereby enable them to relate their understanding 
and practice to appropriate educational principles and key institutional policies. Whilst the first stage of the programme, the Postgraduate Certificate in Third Level Learning and Teaching is required to get tenure, all participants who proceed to the postgraduate diploma are self-selecting and choose to pursue this professional development opportunity themselves for personal learning.

Sharpe et al. (2006) identified transformative course level designs as one of the characterizations of successful blended e-learning. A review of the literature showed that studies repeatedly acknowledged that engaging in course design or redesign was critical to success. The PBL approach in the module at the centre of this study claims to incorporate such transformative potential and can be summarised as including stages of problem identification, deconstruction, seeking and using knowledge and experience, understanding, thinking, choosing a strategy, acting and then critically evaluating and reflecting on the action.

However, there is no specific recipe for mixing up the ingredients of the blend of problem-based learning adopted; the amount of face-to-face, synchronous and self-directed work is prescribed by the learning outcomes of the module itself. Online communication plays a vital role and it is blended with event-based activities, the main ones being the PBL tutorial itself and self-paced learning. However, one of the most exciting opportunities afforded by blended learning experiences and which is central to PBL, is the creation of learning communities. As the development and availability of online tools for communication has led to a concomitant rise in the concept of an online community, Donnelly (2008) advocates that inherent within this is a discussion regarding the consideration of suitable technologies and media choices available in a fluid field such as academic development today. Figure 1 provides a breakdown of the ingredients in the blended PBL module and estimated time for completion of each activity.

Features of a Blended PBL Environment

Face-to-face PBL tutorials

Between tutorials: researching, reading, planning, designing Over 10 weeks ideas

Online reflective journal entries

Video conferencing session

Asynchronous discussions

\section{Duration of Activity}

$10 \times 3$ hours

1 per week x 10 weeks

$3 \times 1$ hours

5 per week x 10 weeks 


\begin{tabular}{ll}
\hline Synchronous chat sessions & $10 \times 30-60$ mins \\
International guest tutor collaboration & $3 \times 1$ week \\
\hline
\end{tabular}

Figure 1 Activities in the Blended PBL Module

In the module design, online components were communication, participation and activity completion and each needed to be considered equally as important as attending any of the live, face-to-face PBL tutorials. Otherwise, there may be a possibility of participants waiting for the live events to obtain the important information. This blended PBL module was designed based on a model originally developed by Oliver (1999) (illustrated in Figure 2).

\begin{tabular}{ll}
\hline \multicolumn{1}{c}{ Learning Design } \\
Elements
\end{tabular}

Figure 2 The Three Learning Design Elements of the Blended PBL Module

From a pedagogical perspective, for an academic developer and a designer and tutor in blended PBL, it is important to seek best practices for how to combine instructional strategies in face-toface and computer-mediated environments that take advantage of the strengths of each and avoid their weaknesses. It is acknowledged that the conjunction of PBL and new technologies which have the potential to facilitate the development of novel pedagogical solutions, implies a challenge for academic staff. For greater transformation of teaching and learning to occur, it is argued that lecturers need appropriate support to make the conceptual shift toward the generation of more sound technology-based learning activities in their practice. 
The module used the WebCT course management system, which provided both asynchronous and synchronous interaction tools. For the former, the module had discussion forums where the participants posted their messages and its own email system that enabled the participants to exchange private emails. For synchronous communications, the module had chat rooms where individuals exchanged instant messages at the same time. By virtue of its online setting, the module web site was accessible from anywhere and at any time. Marratech software was used for video conferencing with guest tutors, and on one occasion, with a peer from the PBL group from abroad.

Along with course design, the tutor's role is readily recognized as central to the success of both PBL and e-learning. In the e-learning literature especially, the tutor is referred to as an emoderator (Salmon, 2000). A hugely important area in any form of instructional delivery is the role of the tutor; in an online environment, it is even more crucial. Each year, two guest tutors from abroad are invited to join the online discussions over a three week period in the module. They are also fellow academic developers internationally, and for many years have been designing and delivering forms of academic professional development, using a combination of online and face-to-face strategies, some of which include problem-based learning.

It can be argued that the impact on the tutor is analogous to the impact a faculty member would find in a classroom setting. A tutor who values a cohesive, supportive and productive blended PBL class can accentuate exchanges of positive affect in learners; they can encourage collective and achievement orientations toward learning in students; they can show appreciation for the uniqueness of each particular learner; and they can facilitate open and diffuse discussions about the problem in a virtual and face-to-face learning environment.

\section{LITERATURE REVIEW}

In the past several years there have been studies conducted into the effectiveness of PBL in a virtual environment in higher education in a number of differing contexts, for example in Ireland (Donnelly 2006b; Jennings, 2006)), in the UK (Juwah, 2002; Valaitis et al., 2005) and in Finland (Portimojärvi, 2006); there has also been recent work conducted into the traditional PBL tutorial in a staff development context (Barrett, 2008). Panda \& Juwah (2006, p. 207) note that the 
increased use of the web for learning and teaching has "necessitated a re-examination of some of the issues with e-learning and the professional development of academic staff engaged in an online facilitation role".

Masie (2006) contends that blended learning has always been a major part of the landscape of training, learning and instruction; however, in reality it has only become a noticeable feature of the higher education sector in Ireland since the beginning of this new millennium. There has been a community of practitioners studying and working in blended courses for many years, nevertheless research in the main has been inadequate.

A central concept of the literature review in blended PBL is how students shift between online and $\mathrm{f} 2 \mathrm{f}$ environments and how they engage in learning and collaborate within the two. This is particularly important to explore within the framework of supporting transformation.

As PBL is consistent with a social constructivist learning pedagogy, one of the challenges faced is to integrate e-learning technologies into PBL where it is appropriate, and where it supports the learner. Within PBL, Ronteltap \& Eurelings (1997) classified PBL activities for learners into two sets and it is based upon these that e-learning technologies were integrated into the module. Information-related learning activities benefit greatly from the vast array of resources available on the Internet to support the research and resource-based searching, selecting, collecting and presentation aspects of the PBL problem. It is argued that the skills of analysis and syntheses still need to be developed within the individual learner and cultivated in the PBL group. Communication and collaboration activities including peer, tutor and international guest expert communications and all support the participants in their questioning, challenging and constructing of knowledge. A third set of activities deliberately integrated into this module are reflective in nature. In a knowledge construction process with learner intention and self consciousness, Jonassen \& Land (2000) suggest that learning activities need the support of reflection and self-regulated learning and the module requires that participants have both the consciousness and capability for both. 
Hanson \& Clem (2006), Hofmann (2006), and Owston et al. (2006) all provide evidence for learners preferring live interactions over those that are computer-mediated in a blended learning experience. It is suggested that these findings are credible because there is a pervasive argument in the literature that there is a synergy that is manifest in face-to-face contact that the computer cannot replicate. Donnelly (2006a) has suggested that discussion forums, chat rooms and email are an adjunct to the PBL group experience by providing the spontaneity and momentum achieved face-to-face in the classroom. However, in contrast to this, Offerman \& Tassava (2006) make the claim from their research that the live components are unnecessary and primarily used for socialisation reasons. This begs the questions, when and why should academics be considering human interaction such as collaboration and learning communities, and how live interaction versus what has been coined by Graham (2006) as low-fidelity (asynchronous) interaction affects the problem-based learning experience.

This study recognises that there is still confusion about the models, media and environments used to support PBL that use technology in some way, and is particularly concerned with illuminating current knowledge on PBL group-oriented interaction. Interaction between participants in the PBL group is the key element to a successful blended learning experience for all involved. This is based on a sociological understanding of one of the dimensions of interaction for describing groups, coined by Wagner (2006) as "interactions as transactions". Interaction has been and continues to be one of the most hotly debated constructs in the realms of distance and e-learning, instructional design and academic transformation, to name but three. The ability to interact - with tutors, students, content interfaces, features, code, channels and environments - can be argued to be analogous to being connected. Whilst this may appear simplistic, for technology-mediated learning, interaction is undoubtedly a key value proposition. It continues to be perceived as the defining attribute for quality and value in a blended learning experience. Interactivity is the core of learning, and is evident at all levels of engagement. However, the term interactivity is used so loosely that in the fields of e-learning and blended learning, it has become almost synonymous with the notion of learning itself. By bringing the concept into sharper focus here, real insight will be gained into the nature of blended PBL. 
Interaction has been explored in the literature at three levels: interaction with concepts, tasks and people (peer learners and tutors). These three levels have been previously represented in a popular framework for interactive learning by Mayes \& Fowler (1999). However, it is suggested that a case can be made for proposing a new dimension of interaction that focuses on the blended PBL interaction activity experience. This was based upon recognition that transformative learning is a complex process of interaction between people, the tools they use and the context in which they are embedded. Today, educators have more choice than ever when it comes to selecting types of interactions to include in their blended courses; unfortunately they often do not even know the potential of the tools that are available to them or how to use then effectively. To further confound the situation, the use of interactive technologies alone does not ensure that meaningful interactions will occur in a blended course. All decisions regarding types of interaction in a blended course should be driven by pedagogical principles and grounded in research.

\section{Research Study: Solutions and Recommendations}

There were two research objectives in this study:

1. To establish, in a PBL tutorial setting the factors that govern the success of blended problem-based learning in order to establish participant learning as transformational;

2. To examine the participants' perspectives on how an e-learning approach to PBL impacts their own learning and practice.

\section{THEORETICAL FRAMEWORK}

Interpretivism was both the paradigm and the methodology for this study. Interpretivism seeks to understand the complex world of lived experience from the perspectives of the participants. As a methodology, it has the goal of analysing, understanding and interpreting the participants' discussions in the face-to-face and online PBL tutorials from their own perspective. The interpretivist emphasis on meaning and the relationship between language and meaning is addressed in the concept of discourse, which in this study is a web of statements, categories, beliefs and practices. The aim of this approach was to explore the research objectives in ways that made connections between the words from the videos and online discussion forum transcripts, the social functions these words perform and wider social practices. 
The analysis of the literature indicated that qualitative data was needed as evidence of the changes that occurred in the nature of blended PBL in the context of academic development in higher education. This decision was arrived at from recognition that transformative learning would be the outcome of a complex process of interaction between people, the tools they use and the context in which they are embedded. I was aware of the difficulty in finding specific example of participants' behaviours or learning that could be identified as transformative. Instead, I was looking for fundamental shifts in participants' orientation towards new knowledge which I expected might manifest itself in changes in their engagement in activities with their peers and tutors.

Interpretivism was chosen to identify the "essence" of human experiences concerning the phenomenon of blended problem-based learning as a model of academic development, as described by the participants in this study. It involved a small number of subjects in extensive and prolonged engagement designed to provide a basis on which to understand their lived experiences and develop what Creswell (1998) calls patterns and relationships of meaning. Consequently, the motivation of this research was to gain a rich insight into the problem-based learning nature of the blended environment rather than focus on the statistical analysis of quantitative responses by participants.

\section{Participants}

The sample for this study was the total population (17 participants) of blended PBL groups undertaking the PBL module in the two years the data was collected, in order to explore the lived experience of a heterogeneous population of academic staff in higher education; there were three PBL groups in this study, and all participants completed the ten week module. Figure 3 shows the breakdown of the background of the participants.

\begin{tabular}{ll}
\hline Number & \multicolumn{1}{c}{ Attribute } \\
\hline 17 & part-time postgraduate learners in total \\
9 & had competed a PBL module previously \\
5 & had prior experience of blended learning \\
\hline
\end{tabular}




\begin{tabular}{ll}
\hline 8 & males \\
9 & females \\
15 & subject disciplines in higher education represented: \\
& Group 1 (psychology, social science, culinary arts, information \\
& literacy, adult literacy); \\
& Group 2 (Biology, Apprentice Plumbing, Apprentice Joinery, \\
& Apprentice Metalwork, Adult Literacy); \\
& Group 3 (Architecture, Marketing, Culinary Arts, Refrigeration, \\
& Printing, Fine Art, Chemistry). \\
&
\end{tabular}

Figure 3 Sample for the Study

\section{METHODS}

The general research design was to observe the process of learning on the module in some depth. In order to ensure that sufficient observational data had been collected for a thorough analysis of what was occurring in the module, three complementary methods were chosen to provide the data relating to the experiences of the participants, in addition to my more obvious tutor role in the module delivery. The research methods employed to collect face-to-face and online observational data were participant observation, online discussion logs, open-ended focus group interviews and self-reflective papers to capture the participant's own thoughts and experiences. Participant observation was the primary method of data collection and occurred with the three blended PBL groups in the module, using video recordings of the face-to-face PBL class tutorials and video recordings of the participant/guest tutor synchronous video conferencing sessions. The PBL tutorial observations for each group were transcribed. The face-to-face classroom and online observation was complemented by two focus group interviews for all three groups. It was important to observe the groups over the complete ten week period of the module in order to examine how the groups negotiated the problem face-to-face and online, how the group dynamics worked in the blended environment, how the life of the group unfolded thereafter and what influenced the participants reaching a transformation in their learning.

Each method was chosen for the opportunity it could offer to explore interactions and dimensions of transformation, both of which were central to this study. A main concern has been to provide meaningful and accessible insights into the practice of blended PBL based on the analysis of real- 
life situations. There were two levels in the analysis of the data. Level One was descriptive in nature and through video observations explored the interactions between the peers, the tutors and the content of the blended PBL tutorial. Level Two was a thematic analysis of transformative learning in blended PBL.

Through the combination of methods, categories and themes emerged to inform the findings of the study and implications for practice. It was important for the researcher to be engaged with the events as they happened in the field and to bring holistic attention to the practices as constitutive of a distinct culture. As suggested by Hine (2000, p. 20), this study has examined those enduring practices through which the blended PBL groups have become meaningful and perceptible to participants.

\section{DISCUSSION OF FINDINGS}

Validity was considered through triangulation of data from the multiple sources (participant observation, textual analysis and focus group interviews) and comparison with other models of academic development; this provided support for assumptions and conclusions. The multiple sources of data provided a rich description of the situation, the factors that impacted on success in a blended PBL tutorial setting and on transformation of learning and practice, along with identification of areas for possible improvement to module design. Presentation of data from all sources allows readers to focus on aspects of particular interest and to draw their own conclusions about the validity of findings.

Whenever possible by using the words of the participants themselves (in line with the ethical considerations adopted for the study, pseudonyms are used throughout), key issues will be highlighted. For inclusion of participant quotes, the following applies: RP = reflective paper.

Module design (illustrated in Figure 4) emphasises what Uden \& Beaumont (2006) have called the close alignment between PBL and ICTs, specifically in the areas of resources, interactive tasks and support. Kiser's research (2002) identifying five core elements of blended learning (use of scenario-based exercises, integration of learning objects, early use of knowledge and skills, access to live mentors and assessments mimicking real world tasks) maps onto PBL and Uden \& 
Beaumont (2006) believe that this reinforces the argument that PBL and e-learning technology can indeed be integrated successfully to the benefit of learners. Furthermore, to summarise, they assert that "the student-centred, task-focused, research-based, collaborative learning characteristics of PBL make it a particularly suitable environment in which to blend technology" (p. 207).

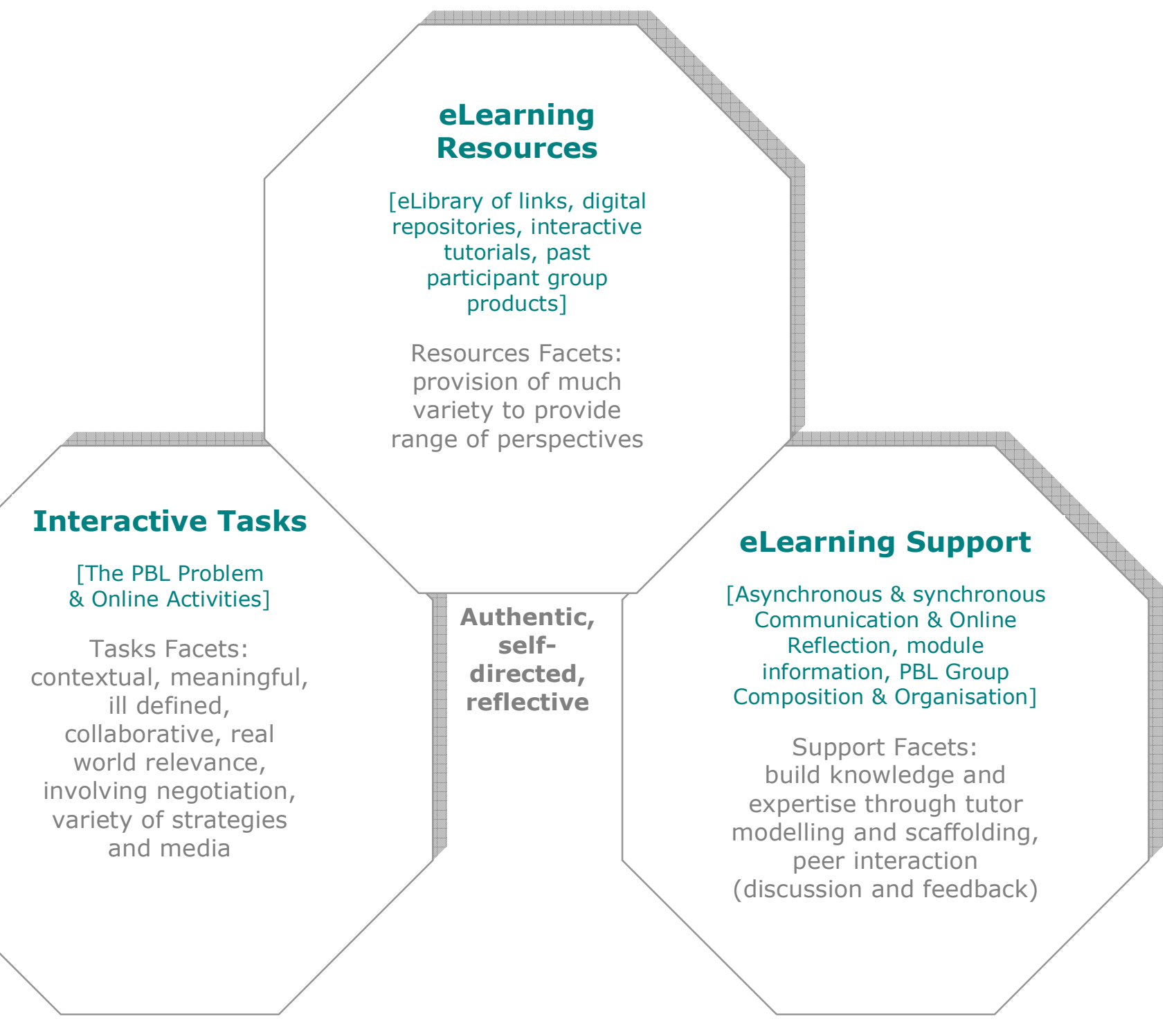

Figure 4 A Design of the Blended PBL Module.

A critical factor in the success of PBL is the provision of appropriate resources for active research and location of information for the solving of the PBL problem. Organisational support information about the module includes: explanation of PBL and links to some key PBL sites; 
roles and responsibilities of the participants; the group composition; expectations of time to be spent online individually and in the PBL group; milestones, deliverables and deadlines for the PBL problem; negotiated group ground rules based on netiquette; a database of frequently asked questions; links to relevant interactive tutorials on web researching, interpersonal communications, conflict resolution, self and peer assessment strategies within PBL; and participant home pages. The intention is to provide a dynamic website, to complement the $2 \mathrm{f}$ PBL weekly tutorials and adapt to the participant group experience and progression of the PBL Problem.

It is the essentially rich environment of synchronous and asynchronous communication tools that truly support distributed (virtual) PBL. Group working and associated communication is a vital component of PBL and it is dependent on participant collaboration for its success. Again, it is argued that e-learning technology should only be used if it adds value to the existing f2f tutorial sessions. It is interesting to note that a review by Ronteltap et al. (2004) at the University of Maastricht, a higher education institution famed for its use of PBL, prioritised the use of communication tools because planned f $2 \mathrm{f}$ meetings "appeared to be insufficiently supportive of the learning process" (p. 274). This enthusiasm has been tempered by the realisation that one of the most challenging tasks is to design and facilitate an effective communication space for any form of online learning, including PBL.

The interactive use of e-learning in this module is the process-supporting kind, making use of the technologies of discussion forums, chat rooms, video and audio conferencing to link to live international experts, blogging software and what Buzan \& Buzan (1996) have termed mind mapping techniques, with supporting software. Building semantic links in this way represents information more visually and also uses more than one dimension. In the past, Schank et al. (1995) have reported other software explored by researchers which was specific to social and cognitive process support. One such example was by Koschmann et al. (1996), who worked on developing a comprehensive computer-supported environment for PBL. What is interesting about their work is their suggested use of technological supports needing to subtly change pedagogy - a theme that has since been enhanced and propagated in e-learning research ever since. 
Bereiter \& Scardamalia (2000) picked up on ways that e-learning technology could truly addvalue to the process of PBL. A particular benefit occurs in the directive tutor's role which Donnelly (2006a) reported as having a three-fold impact: the tutor encouraging a more equal relationship with the participants; the tutor-dependent students' role; and disparities in student participation and involvement. In this blended PBL model, the tutor is no longer at the centre of the communications web. The asynchronous nature of the online discussions means that participants do not have to capture a conversational turn to contribute to discussions and so it becomes less likely that a few participants will dominate. Conversely, in this same medium, the more reticent or less verbal participant may also benefit from having more time to formulate a response. Of course, such a rosy picture in itself can be misleading.

Donnelly (2004) reports from a survey of the literature, that there appears to be significant opportunity in PBL for the use of asynchronous forums. Based on this, threaded discussion postings are used on the module for posing questions, arguing positions and challenging statements, achieving consensus and co-constructing meanings about e-learning. At the same time, Donnelly \& O'Rourke (2007) contend there is a plethora of research reporting difficulties generally with participation in online discussions. Particularly with campus-based students, the use of discussion forums can be regarded as an imposition by students unless they can see that the discussion relates to their study and that the discussion forum is an appropriate location and medium for the interaction. Once students are convinced of the benefits of sharing references and sources, it can galvanise the group into getting started. Palmer (1998) believes a teaching and learning space needs to be more than a form for individual expression; it must also be a place in which the group's voice is gathered and amplified, so that the group can affirm, question, challenge and correct the voice of the individual. Sustained asynchronous collaboration over time remains to this day a problematic area. Whilst learning can demand solitude, it also demands community, a dialogical exchange in which our ideas can be tested, our biases challenged, our knowledge expanded and even our ignorance aired; all of which is best served with others, rather than in an exchange in which we are simply alone with our thoughts. Alongside this, it is recognised that there is difficulty entailed in such endeavours in an online forum. Bereiter \& Scardamalia (2000, p. 193) rightly argue that "utilising an educational approach with the high 
aspirations of PBL means looking for ways to make participation cognitively more rewarding to the students".

There is a growing emergence of the use of synchronous forums for supporting PBL (Portimojärvi, 2006). Each year newer technologies are ensuring that synchronous communication is becoming even more ubiquitous amongst students and arguably teachers need to follow suit. Some claims of preference for one medium over the other have been too hastily accepted and in their research, Chew \& Beaumont (2004) found that an integrated set of synchronous and asynchronous tools were important within a distributed PBL environment.

Resolving the tension over which medium to use seems to be a perpetual task for the educator. The fissure is particularly acute in this debate over synchronous vs. asynchronous delivery. At the turn of the century, McFerrin (1999) reported on studies highlighting the benefits of online communication by extending classroom discussions, improving interaction between student and teacher (Collins, 1998) and increasing time-management ability, self-directive behaviour, selfconfidence and self-discipline. Yet today a common problem for some academic staff is that they find asynchronous facilities a hindrance rather than a help to learning. Students too are reluctant to use them in a formal academic setting for a number of reasons, in contrast to the growing popularity of social networking sites such as those provided by, for example, "Bebo" and "Facebook"; asynchronous interaction can inhibit spontaneous development of ideas; in collaborative problems, a student may also make significant progress down the wrong path through research or practice before his or her group-mates can correct an improper understanding of that student's role in the group for that particular assignment. In addition, Garrison \& Anderson (2003) have reported that asynchronous interaction inhibits the quick allocation of tasks and formation of schedules to get problem-solving activities completed. Furthermore as traditional face-to-face group dynamics can still tend to be the benchmark by which the value of the learning-teaching experience is judged, online pedagogies are frequently valued by academic staff only in proportion to how well they seem to reproduce or simulate an equivalent face-to-face experience. Where this fails (as it often does) lecturers may revert to using the virtual learning environment as a method for distributing lecture notes, or may simply abandon using it altogether. 
Figure 5 shows the implementation of the blended PBL model of academic development proposed in this study. Colour is used to show at a glance those components that are face-to-face (outlined in green), those that are fully online (outlined in blue) and the blended components (outlined in purple). The WebCT courseware management system is highlighted in grey. The discourse in the PBL tutorial is supported with activities such as guided reflection, guest seminars, demonstrations of the technologies and peer evaluation. The online components of the blend include some course management standard features such as student homepages, online timetables and a set of personal individual progress statistics. These are augmented by virtual PBL tutorials which encompass online activities such as discussions, presentations, formative assessments and delivered using a set of tools such as video conferencing, podcasting, discussion forums, chat rooms and interactive tutorials. 


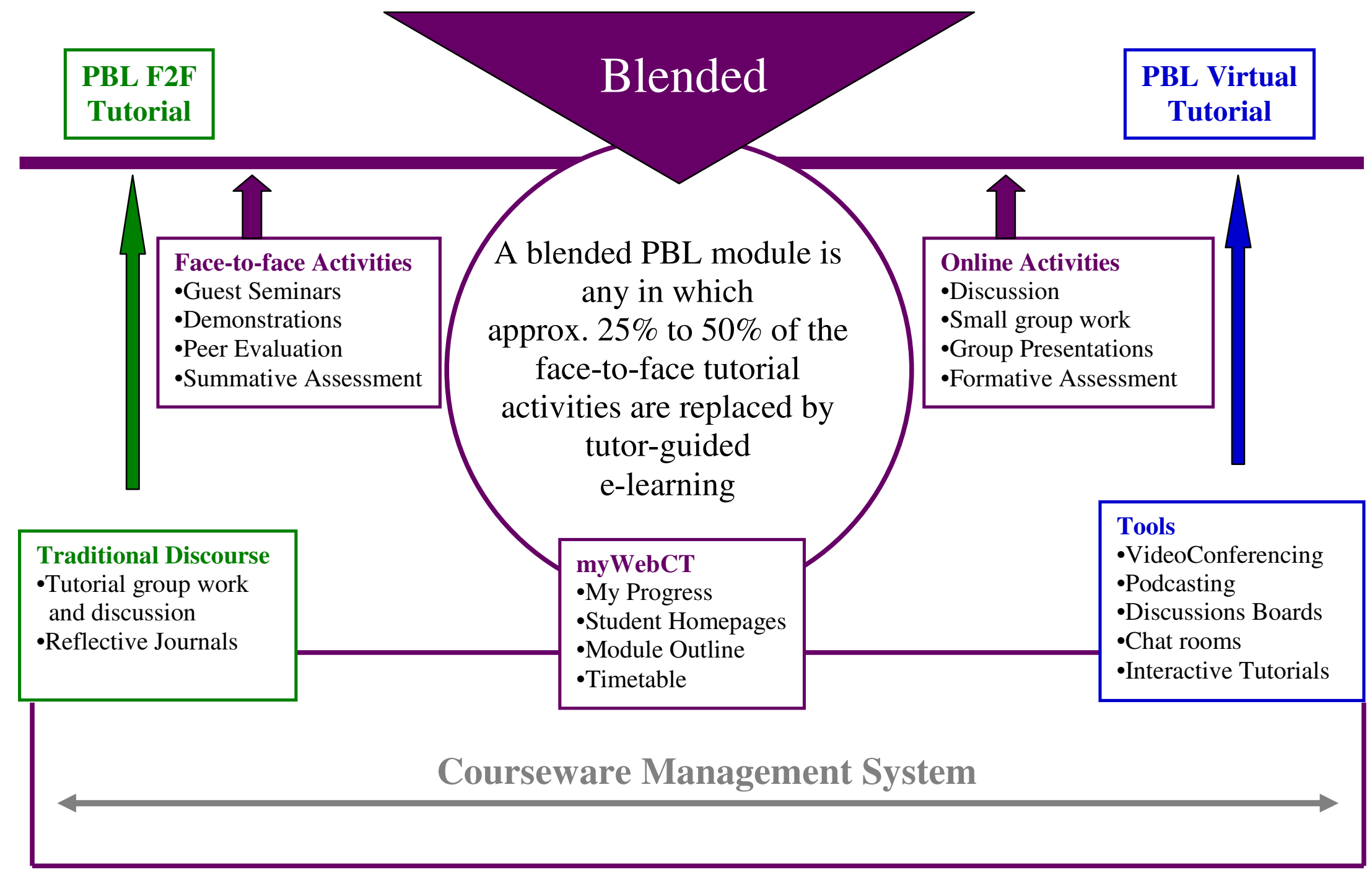

Figure 5 The Implementation of the Blended PBL Module 
Drilling down to explore levels of interaction spanning the $\mathrm{f} 2 \mathrm{f}$ and online environments is key on this study. Figure 6 represents the different levels of activity and interaction in the blended PBL tutorial at three key stages in the ten week module at week 1, at the half way point (week 5), and at the close of the module (week 10). The PBL tutorial is shown in a face-to-face setting and also in its online environment. At week 1 , the interaction is fully between the participants and their tutor separately in the face-to-face and online tutorial. At this stage, there is little crossover of interaction between the two environments. By week 5, there is much more cross-over of interaction between the face-to-face and online tutorials. Guest international tutors are introduced to participants and the deepest and most prolonged online discussions of the entire module occur at this juncture. Towards the close of the module, at week 10, the focus of the participants is on the PBL content and their end product and once again there is little intersection of interaction types in the blend. 


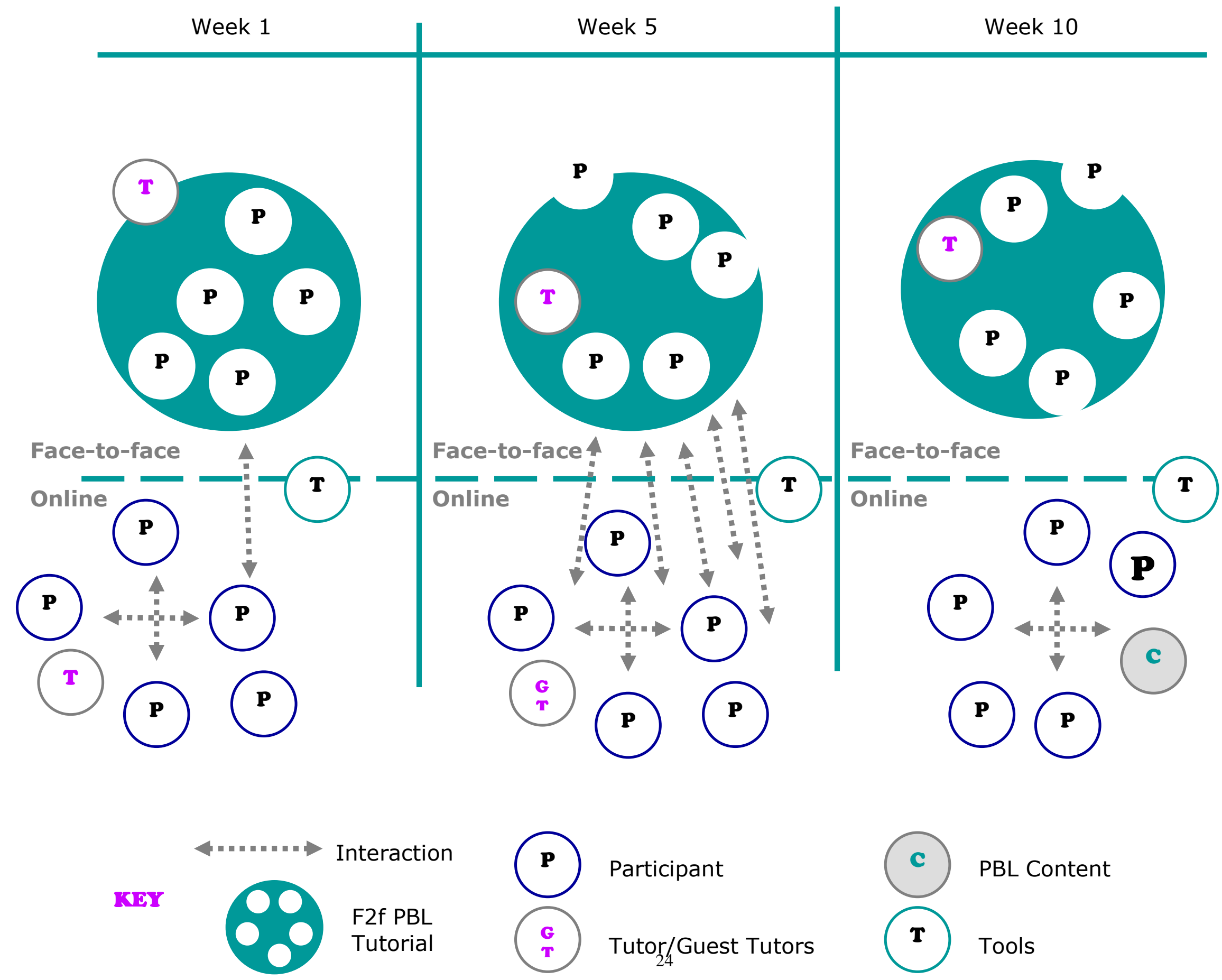

Figure 6 Levels of Activity within the Blended PBL Approach 
Deep learning often involves the element of time, but the findings suggest a theoretical possibility for deep learning in 10 weeks. These professional practitioners made strides towards transformative learning through change in their cognitive structure and reflection. The participants transformed their frames of reference so that they could best appreciate and understand their own experience on the module.

Change does not come easy to individuals or institutions for that matter. We are all creatures of habit. Our institutions will have to initiate and adapt training programs in order to prepare lecturers for the increased expectations of the 'new' student that is emerging. This is essential as learning is becoming more self directed. (Declan, RP15)

For transformative learning to take place for me, new learning needs to challenges parts of the existing framework of assumptions, beliefs and thinking processes. To facilitate this transformation in my learning it is necessary to reflect on experiences on the module and undergo an ordered, systematic, structured, deliberate, logical analysis of events and situations. (Eimear, RP6)

This research has suggested that blended PBL might lead to an enduring transformation in teaching practice. However, change in departments proceed in slow, linear, incremental steps improving, expanding, contracting, and reforming - without altering its fundamental institutional mission, approach, or structure. Whilst this observation on change is neither new nor the preserve of the academic institution alone, it points to the importance of never losing sight of the state of affairs on the ground. Of course, transforming a departmental approach to learning and teaching in such a complex phenomenon as the higher education institution is neither linear nor predictable. Transformation is an iterative process, since as an institution proceeds, experience leads to learning that can modify the transformation process.

As we would expect, questions about pedagogy and technology are inseparable in this study. The pedagogical innovations and module design are as integral to the investigations on transformative learning as the technologies being drawn upon. It is not the purpose of this study to examine the impact of technology in isolation from these larger transformations in teaching and learning. What this research wanted to track is the interaction and interdependence of innovative pedagogies such as PBL and new media technologies. 
In looking at the nature of transformation on the module, several overlapping categories of questions emerge. First, there are questions about shifting the time and space for learning. Looking at the impact of online communication tools to connect participants on the module to experts in other countries, shifting time and space implies the possibilities of connecting the classroom to resources in the community. Second, there are questions about getting the participants to slow down and document the process of learning through critical reflection. Third, there are questions about how academic developers can best support academic staff in adopting a learning approach and a change to teaching practice that differs from what they have previously experienced.

It was important for all participants to step back from the module in order to reflect upon and understand the impact of contextual issues that may have been cultural, social or even economic on thinking and professional practice. If transformative learning is to take place and a more holistic approach to academic development cultivated, these most ingrained assumptions have to be recognized and questioned. These may not have been fully and universally borne out but an insight provided by Nobel Laureate Herbert Simon (1982, p. 46), does bring us to a place where we are better able to witness a transformation in learning: "for the computer to bring about a revolution in higher education, its introduction must be accompanied by improvements in our understanding of teaching and learning."

Bach et al. (2007) suggest that the continuing rapid pace of change and evolution is unlikely to lead to a singular and idealistic outcome where technology inspires a very large transformation of the quality of learning that empowers students. However, in their view, technology will continue to offer some real opportunities to increase the quality of learning and teaching, and in my view transform the learning experience for the individual lecturer within a problem-based learning context. Giroux (1988, p127) coined the phrase "teachers as transformative intellectuals" and has suggested that we use forms of pedagogy that treat students as critical agents, make knowledge problematic and utilise critical and affirming dialogue. This he argues in part suggests that transformative intellectuals take seriously the need to give students an active voice in their learning experiences. This voice and the ongoing commitment of the module participants is evidenced by two of the groups having published a chapter on their transformative experiences of 
the module. Instilled confidence from the module was evidenced by a number of participants from each of the three groups presenting their ongoing work at a number of recent national and international conferences including Educational Technology of Ireland 06 and International Technology, Education and Development (INTED) 07, all under blended learning streams.

In implementing a constructivist learning approach in blended problem-based learning on this module, some aspects of constructivist learning may be directly stimulated by technology, notably an increased level of collaboration, heterogeneity of roles and greater complexity and authenticity in assigned tasks. Other aspects, such as involvement with content that incorporates multiple academic disciplines may not be influenced by technology per se, but are often reinforced by technology use.

\section{CONCLUSION}

This final section provides the conclusions of this study, a contemplation of what will happen after the study, including what other avenues are open for exploration, along with critical reflection about the ultimate application or use of the research. This study was an attempt to provide insights into blended PBL in a higher education academic development context in order to encourage in-depth discussion and open debate on the field. One of the main challenges faced by today's academic developers is the development of e-learning technologies to support constructivist and social constructivist teaching and learning approaches among the academic staff with whom they work so that this is, in turn, is carried forward into their own classrooms and subject disciplines (Donnelly, 2006a).

Figure 7 shows which elements of the blend are best conducted face-to-face, and which work best online.

\begin{tabular}{ll}
\hline Face-to-face & Online \\
\hline $\begin{array}{l}\text { Induction involving ICT skills training, } \\
\text { icebreaker and socialization sessions and } \\
\text { introduction to PBL }\end{array}$ & Reflective journals \\
Brainstorming & Sharing resources \\
\hline
\end{tabular}




\section{Utilising the online library and ebooks}

\begin{tabular}{ll} 
Critiquing peer ideas & $\begin{array}{l}\text { Interdisciplinary international experts } \\
\text { dialoging through video conferencing and } \\
\text { asynchronous forums } \\
\text { Positive peer feedback } \\
\text { (both seeking and giving) }\end{array}$ \\
Sharing peer experiences & $\begin{array}{l}\text { Online peer tutoring and support with } \\
\text { technical problems }\end{array}$ \\
\hline $\begin{array}{l}\text { Resources: involving past graduates of the } \\
\text { module }\end{array}$ &
\end{tabular}

Figure $7 \quad$ Blended Ingredients that Proved Effective

The findings in this study indicated a preference for live tools in the blending of PBL and eLearning, specifically the face-to-face PBL tutorial. Of the online tools utilized in the module, the online reflective journals were the most favoured. The blending of delivery mechanisms (online and face-to-face), instructional approaches such as PBL and technologies such as asynchronous and synchronous discussions, video conferencing and online reflection have shown potential in evolving to support collaborative and interactive learning. From a design perspective, it is useful to employ a holistic approach to blending media and activities. Developing technical competencies and pedagogical skills in tandem and via authentic tasks, provides the learners with technological skills to succeed in both face-to-face and computer-mediated environments.

Worldwide, higher education institutions are using formal, accredited courses for academic staff as a vehicle for diffusion of staff development in new learning technologies. It is still arguable that a new cadre of teachers in higher education need an understanding of the dynamics of online communication and interactions; this study has suggested that alongside needing to learn effective ways of facilitating and teaching online, a change in attitude, values and beliefs will develop confidence for ongoing learning.

\section{Future Trends}

To fully understand the journey of transformation, there are some key points worth remembering; there is no set timetable for this journey as some participants move through some stages more quickly than others; comfort level, interest, technology access and time are important 
determinants of any individual's timeline. When institutions in higher education recognize the need to learn technology and pedagogy as an opportunity to transform teaching and learning, this can open up new opportunities for all involved. Figure 8 summarises blended PBL today and what needs to be considered for academic developers in the future, when designing and tutoring in this field.

\begin{tabular}{|c|c|}
\hline Blended PBL Today & $\begin{array}{l}\text { Considerations for Academic } \\
\text { Development Tomorrow }\end{array}$ \\
\hline $\begin{array}{l}\text { Tutors facilitate; students do, present, } \\
\text { think, construct } \\
\text { Working together facilitates learning and } \\
\text { problem solving } \\
\text { Subjects are integrated into a learning } \\
\text { whole } \\
\text { Learning is problem-centred } \\
\text { There are many rich resources for learning } \\
\text { Concepts are explored using a variety of } \\
\text { media } \\
\text { Assessment is based on each student's } \\
\text { developing abilities to solve problems to } \\
\text { communicate ideas, present information, } \\
\text { and learn how to learn } \\
\text { Technology connects the world to the } \\
\text { classroom vice versa }\end{array}$ & $\begin{array}{l}\text { To help teachers: } \\
\text { - } \quad \text { find ways to exploit the capacities } \\
\text { offered by new technologies; } \\
\text { - } \quad \text { to acknowledge the ever-changing } \\
\text { nature of the e-landscape; } \\
\text { - } \quad \text { to be aware of a more robust body of } \\
\text { theory and practice on blended } \\
\text { learning; } \\
\text { This will require a careful process of } \\
\text { ensuring collaboration between tutors and } \\
\text { experts, gaining successful experience in } \\
\text { teaching with the technologies and } \\
\text { participating in a community that provides } \\
\text { continuous support. }\end{array}$ \\
\hline
\end{tabular}

Figure $8 \quad$ Current and Future Considerations of Blended PBL

Although generalisability was not an intention of this study and no groups are the same, for future research, an intention is to replicate the study with other groups to see if the conclusions are sustained. This additional research across other groups could be used to determine how widespread the interpretations are. The study focused on how the participants in the groups interacted with one another in a blended environment and to an extent the learning that was transferred to professional practice. Applying Activity Theory as an analytical tool for representation to support the analysis of the differences/similarities across different learning groups in blended PBL is also a promising area for future research, as is a focus on the interplay between the levels of transformative learning reached in blended PBL academic development and its actual impact on students' learning in different disciplines. 


\section{REFERENCES}

Bach, S., Haynes, P., \& Smith, J.L. (2007). Online Learning and Teaching in Higher Education. Maidenhead: Open University Press.

Barrett, T. (2008). Students Talk About Problem-based Learning in PBL Tutorials: Illuminative Concepts. Unpublished doctoral dissertation, Coventry University, UK.

Bereiter, C., \& Scardamalia, M. (2000). Commentary on Part 1: Process and Product in Problembased Learning (PBL) Research. In D.H. Evensen \& C.E. Hmelo (Eds.), Problem-based Learning. A Research Perspective on Learning Interactions (pp.185-195). Mahwah, NJ: Lawrence Erlbaum Associates.

Buzan, T., \& Buzan, B. (1996). The Mind Map Book: How to Use Radiant Thinking to Maximise your Brain's Untapped Potential (reprint ed.). New York: Plume Books.

Chew, S.C., \& Beaumont, C. (2004, June). Evaluating the effectiveness of ICT to support globally distributed PBL teams. Paper presented at the ITiCSE Conference, ACM/SIGCSE, (pp. 47-51).

Collins, M. (1998). The use of email and electronic bulletin boards in college-level biology. Journal of Computers in Mathematics and Science Teaching, 17(1), 75-94.

Creswell, J. (1998). Qualitative Inquiry and Research Design: Choosing Among Five Traditions. Thousand Oaks CA: Sage Publications.

Donnelly, R. (2004). The effectiveness of teaching 'Online Learning' in a problem-based learning classroom environment. In M. Savin-Baden \& K. Wilkie (Eds.), Challenging Research into Problem-based learning. Buckingham: Open University Press.

Donnelly, R. (2006a). Blended problem-based learning for teacher education: lessons learnt. Journal of Learning, Media and Technology, 31(2), 93-116.

Donnelly, R. (2006b). The Academic Developer as Tutor in PBLonline in Higher Education. In M. Savin-Baden \& K. Wilkie (Eds.), Problem-based Learning Online (pp. 79-97). Maidenhead: Open University Press.

Donnelly, R. (2008). Virtual Problem-based Learning Communities of Practice for Teachers and Teacher Educators: An Irish Higher Education Perspective. In C. Kimble \& P. Hildreth (Eds.), Communities of Practice: Creating Learning Environments for Educators. USA: Information Age Publishing.

Donnelly, R., \& O'Farrell, C. (2006). Blended E-Learning for Continuous Professional Development of Academic Staff. In J. O'Donoghue (Ed.), Technology Supported Learning and Teaching: A Staff Perspective. Hershey PA: Information Science Publishing. 
Donnelly, R., \& O'Rourke, K. (2007). What now? A critical evaluation of e-learning CPD practice in Irish third level education. Journal of Further \& Higher Education.

Garrison, D.R., \& Anderson, T. (2003). E-learning in the $21^{\text {st }}$ Century. A Framework for Research and Practice. London: RoutledgeFalmer.

Giroux, H.A. (1988). Teachers as Intellectuals. Towards a Critical Pedagogy of Learning. Critical Studies in Education Series. New York: Bergin \& Garvey.

Graham, C. (2006). Blended Learning Systems: Definition, Current Trends, and Future Directions. In C.J. Bonk \& C.R. Graham (Eds.), The Handbook of Blended Learning. Global Perspectives, Local Designs (pp. 3-21). San Francisco: Pfeiffer.

Ham, V., \& Davey, R. (2005). Our first time: two higher education tutors reflect on becoming a 'virtual teacher'. Innovations in Education and Teaching International, 42(3), 257-264.

Hanson, K., \& Clem, F. (2006). To Blend or Not to Blend: A Look at Community Development Via Blended Learning Strategies. In C.J. Bonk \& C.R. Graham (Eds.), The Handbook of Blended Learning. Global Perspectives, Local Designs (pp.136-149). San Francisco: Pfeiffer.

Hine, C. (2000). Virtual Ethnography. London: Sage.

Hoare, S. (2006). The Guardian, Tuesday June 20 2006. Retrieved September 24, 2008, from http://www.guardian.co.uk/education/2006/jun/20/elearning.technology15

Hofmann, J. (2006). Why Blended Learning Hasn't (Yet) Fulfilled Its Promises: Answers To Those Questions That Keep You Up at Night. In C.J. Bonk \& C.R. Graham (Eds.), The Handbook of Blended Learning. Global Perspectives, Local Designs (pp. 27-40). San Francisco: Pfeiffer.

Jennings, D. (2006). PBLonline: A Framework for Collaborative e-Learning. In M. Savin-Baden \& K. Wilkie (Eds.), Problem-based Learning Online (pp. 105-123). Maidenhead: Open University Press.

Jonassen, D., \& Land, S. (2000). (Eds.) Theoretical Foundations of Learning Environments. Mahwah, NJ: L. Erlbaum Associates.

Juwah, C. (2002). Using communication and information technologies to support problem-based learning. HEA Academy. Retrieved February 28, 2007, from http://www.heacademy.ac.uk

Kirkup, G., \& Kirkwood, A. (2005). Information and communications technologies (ICT) in higher education teaching: A tale of gradualism rather than revolution. Learning, Media and Technology, 30(2), 185-199.

Kiser, K. (2002). Is blended best? E-learning Magazine. Retrieved July 31, 2006, from http://www.elearningmag.com/elearning/article/articleDetail.jsp?id=21259 
Koschmann, T.D., Kelson, A.C., Feltovich, P.J., \& Barrows, H.S. (1996). Computer-supported Problem-based Learning: A Principled Approach to the Use of Computers in Collaborative Learning. In T.D. Koschmann (Ed.), CSCL: Theory and Practice of an Emerging Paradigm (pp. 83-124). Hillsdale, NJ: Lawrence Erlbaum Associates.

McFerrin, K.M. (1999, February). Incidental Learning in a Higher Education Asynchronous Online Distance Course. In J.D.Price, J. Willis, M. Jost, \& S. Boger-Mehall (Eds.), SITE 99: Proceedings of the Society for Information Technology \& Teacher education International Conference, San Antonio TX (Charlotteville VA, Association for the Advancement of Computers in Education (AACE)), (pp. 1418-1423).

Masie, E. (2006). The Blended Learning Imperative. In C.J. Bonk \& C.R. Graham (Eds.), The Handbook of Blended Learning. Global Perspectives, Local Designs (pp. 22-26). San Francisco: Pfeiffer.

Mayes, J.T., \& Fowler, C.J.H. (1999). Learning technology and usability: a framework for understanding courseware. Interacting with Computers, 11, 485-497.

Myers, S.A. (2006). Can I use transformative pedagogy when teaching online? College Teaching, 2(1), 82-94.

Offerman, M. \& Tassava, C. (2006). A Different Perspective on Blended Learning: Asserting the efficacy of Online Learning at Capella University. In C.J. Bonk \& C.R. Graham (Eds.), The Handbook of Blended Learning. Global Perspectives, Local Designs (pp. 516-528). San Francisco: Pfeiffer.

Oliver, R. (1999). Exploring strategies for online teaching and learning. Distance Education, 20(2), 240-254.

Owston, R., Garrison, D., \& Cook, K. (2006). Blended learning at Canadian universities: issues and practices. In C.J. Bonk \& C.R. Graham (Eds.) The Handbook of Blended Learning. Global Perspectives, Local Designs (pp. 338-350). San Francisco: Pfeiffer.

Palmer, P. (1998). The Courage to Teach: Exploring the Inner Landscape of a Teacher's Life. San Francisco, CA: Jossey-Bass.

Panda, S., \& Juwah, C. (2006). Professional Development of Online Facilitators in Enhancing Interactions and Engagement: A Framework. In C. Juwah (Ed.), Interactions in Online Education. Implications for Theory and Practice. London: Routledge.

Portimojärvi, T. (2006) Synchronous and Asynchronous Communication in Online Problembased Learning. In Verkkovirityksiä - ongelmaperustainen oppiminen ja projektioppiminen verkossa.

Ronteltap, C.F.M., \& Eurelings, A.M.C. (1997). POLARIS: The Functional Design of an Electronic Learning Environment to Support Problem-based Learning. In T. Müldner \& T.C. 
Reeves (Eds.), Educational Multimedia and Hypermedia. Charlottesville: Association for the Advancement of Computing in Education (pp. 1802-1807).

Ronteltap, C.F.M., Goodyear, P., \& Bartoluzzi, S. (2004). A pattern language as an instrument in designing for productive learning conversations. World Conference on Educational Multimedia, Hypermedia and Telecommunications, 1, 4271-4276.

Salmon, G. (2000). E-Moderating. The Key to Teaching and Learning Online. London: Kogan Page.

Savin-Baden, M. (2006). The challenge of using problem-based learning online. In M. SavinBaden \& K. Wilkie (Eds.) Problem-based Learning Online (pp. 3-13). Maidenhead: Open University Press.

Schank, P., Ranney, M., \& Hoadley, C. (1995). Convince Me [Computer Programe and Manual]. In J.R. Jungck, N. Peterson \& J.N. Calley (Eds.), The BioQuest Library. College Park, MD: Academic Software Development Group, University of Maryland.

Sharpe, R., Benfield, G., Roberts, G., \& Francis, R. (2006). The undergraduate experience of blended e-learning: a review of UK literature and practice, Retrieved December 12, 2006, from http://www.heacademy.ac.uk/4884.htm

Simon, H. (1982). Sciences of the Artificial. Cambridge, MA: The MIT Press.

Uden, L., \& Beaumont, C. (2006). Technology and Problem-Based Learning. Hershey, PA, USA: Information Science Publishing.

Valaitis, R.K., Sword, W.A., Jones, B., \& Hodges, A. (2005). Problem-based learning online: perceptions of health science students. Advances in Health Sciences Education, 10, 231-252.

Wagner, E.D. (2006). On Designing Interaction Experiences for the Next Generation of Blended Learning. In C.J. Bonk \& C.R. Graham (Eds.) The Handbook of Blended Learning. Global Perspectives, Local Designs (pp. 41-55). San Francisco: Pfeiffer. 